\title{
High-Resolution, Near Real-Time Simulation of Microwave Radiance Using a Simple Land-Cover Based Emissivity Prior
}

\author{
Dimitrios Katsanos, ${ }^{1,2}$ Eduardo García-Ortega, ${ }^{3}$ Manuel de Castro, ${ }^{1,4}$ \\ Enrique Arias, ${ }^{5}$ and Francisco J. Tapiador ${ }^{1,4}$ \\ ${ }^{1}$ Faculty of Environmental Sciences and Biochemistry, UCLM, 45071 Toledo, Spain \\ ${ }^{2}$ National Observatory of Athens, IERSD, 15236 Athens, Greece \\ ${ }^{3}$ Atmospheric Physics Group, Environment Institute, ULE, 24071 León, Spain \\ ${ }^{4}$ Institute of Environmental Sciences (ICAM), 45071 Toledo, Spain \\ ${ }^{5}$ Computing Systems Department, UCLM, 02071 Albacete, Spain
}

Correspondence should be addressed to Dimitrios Katsanos; katsanos@noa.gr

Received 16 December 2013; Revised 8 March 2014; Accepted 8 March 2014; Published 10 April 2014

Academic Editor: Luis Gimeno

Copyright (C) 2014 Dimitrios Katsanos et al. This is an open access article distributed under the Creative Commons Attribution License, which permits unrestricted use, distribution, and reproduction in any medium, provided the original work is properly cited.

Satellite simulators are used to calculate the brightness temperature $\left(T_{b}\right)$ that would be measured by a space borne sensor under a set of atmospheric conditions accounting for the radiometric characteristics of the sensor and the orbital parameters of the satellite. In this study, a simple approach is proposed for the parameterization of emissivity over land, a key parameter for the calculation of microwave $T_{b}$. The rationale is to simulate a large ensemble of emissivity values for each frequency and surface characteristics and then relate the most likely observed value with soil characteristics. The derived emissivity values are used for the simulation of $T_{b}$ and simulated radiance is then compared with satellite observations. It is shown that this method improves the simulation of radiance and that it is suitable to provide a first guess of the emissivity value (a prior) that can then be refined using iterative procedures.

\section{Introduction}

Satellite observations have been instrumental to monitor precipitation and clouds at global scale over the last three decades [1]. The availability of satellite data has increased rapidly, providing scientists with better precipitation estimates over areas with sparse or even without in situ measurements (see [2] for a review). Algorithms relating observed $T_{b}$ values with precipitation have evolved from simple band ratios to more complex treatments of radiance. Towards that direction is the development of multisensory satellite simulators, which are used to create synthetic measurements for various satellite platforms, computed with meteorological parameters, virtually representing the atmospheric and ground state [3]. However, retrievals are difficult to perform over land because, at microwave (MW) wavelengths, the surface contributes to the measured radiation [4]. High and variable emissivity at such frequencies complicate retrieving the signal from hydrometeors [5]. Even small errors in the emissivity prior can result in important errors in the $T_{b}$ calculated through radiative transfer methods. Therefore, it is critical to compute or estimate microwave emissivity as close as possible to the real values.

Over oceans and water bodies the emissivity is relatively low (between 0.4 and 0.5 ). Emissivity models over those surfaces produce realistic results because the parameters that affect the value of emissivity, namely wind speed, sea surface temperature and salinity, can be easily parameterized.

In contrast, over land emissivity is higher and depends on parameters that cannot be so easily parameterized [6]. Among others, emissivity varies with surface types and season since it is dependent on factors that vary temporally, such as soil moisture and surface roughness, both of which also depend on vegetation. Emissivity is generally more 
anisotropic over forests than over bare soils due to absorption and scattering within the canopy [7] and is also greatly affected by the presence of surface water and snow [8]. More importantly in terms of near real times estimates, emissivity at the MW frequencies exhibits a noticeable diurnal variability related with soil moisture and dew formation [9]. Overall, radiative transfer methods in the MW over land are known to produce less accurate results compared with those over the sea $[10,11]$, the complexity of the surface playing a main role. Thus, vegetation attenuates the increase in emissivity produced by soil moisture, but the effect is masked out in the presence of high or broadleaved trees [12]. It has been observed that emissivity in the microwave region increases with frequency and vegetation cover and decreases with soil moisture mainly for nonvegetated areas and also that emissivity increases with vegetation density: forests zones are associated with values close to 1 (0.98-0.99). Given the many possible ways those factors may combine, the temporal variation of those, and the patchy nature of many landscapes, it is not surprising that precise estimation of emissivity over land remains elusive.

An approach for tackling the problem of estimating microwave emissivity over land consists in using climatology to provide a first guess (a prior) for further refinement. Thus [8] have produced global atlases of emissivity values based on satellite measurements of brightness temperatures. The socalled TELSEM atlases consist of tables with mean monthly values of microwave emissivity in 4 frequencies $(23,31,50$, and $89 \mathrm{GHz}$ in both vertical and horizontal polarizations) interpolated over a grid of 0.25 degrees. The main goal of such database is to feed a radiative transfer simulator of microwave brightness temperatures with the prior, as shown in [13] using the RTTOV package.

This paper follows a different approach. In the present study, the emissivity values over land in a high-resolution $(3 \mathrm{~km})$ grid are estimated using NWP model parameters, such as vegetation type, in order to produce a table of emissivity values, for each frequency channel per vegetation type. Thus, each land pixel will have its own emissivity value depending on the vegetation type given by the NWP model. The aim is to implement these emissivity values in a microwave brightness temperature satellite simulator for high-resolution runs.

\section{Radiative Transfer Simulations}

2.1. Radiative Transfer (RT) Code. In this paper, the Satellite Data Simulator Unit (SDSU) developed by H. Masunaga is applied. It can be used to simulate microwave brightness temperature, radar reflectivity, and visible/infrared radiance; the same way meteorological satellite sensors would measure these parameters. In other words, it produces synthetic satellite data similar to those that the spaceborne sensor would produce if it were flying over a specific region. Radiative transfer codes are implemented with Mie-theorybased subroutines to compute the radiative properties of cloud and precipitating hydrometeors as well as a gas absorption database covering a broad range of electromagnetic spectrum. A beam-convolution program is also provided so

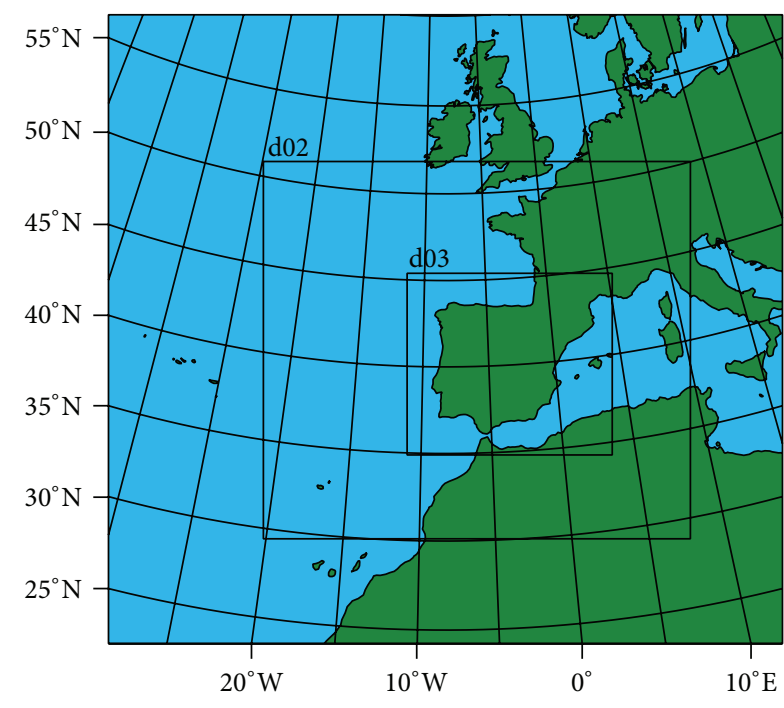

FIGURE 1: WRF model domains used for the simulations.

that the nonuniform beam filling effect is taken into account for an arbitrary field-of-view (FOV) size.

The most important applications of SDSU are (a) the evaluation of cloud resolving models [14] and (b) the use of the simulations in the development of rain retrieval algorithms $[14,15]$.

Currently, the outputs of high-resolution NWP models are used as input for the SDSU, as in the case of Goddard SDSU, which is built upon the original version of SDSU and simulates satellite consistent measurements from inputs obtained from the Goddard multiscale modelling system with unified physics [16].

2.2. Numerical Weather Prediction (NWP) Model. As a CRM that provides the SDSU inputs, the weather research and forecasting (WRF) model, is used instead, for the Iberian Peninsula in $3-\mathrm{km}$ resolution. The WRF model [17] is a numerical weather prediction (NWP) model that has been used for a wide range of applications, from idealized research to operational forecasting. When used at horizontal grid resolution in the range of $1-5 \mathrm{~km}, \mathrm{WRF}$ is a CRM explicitly simulating precipitation without the need for parameterization of the convection process.

In the framework of this study, the ARW version 3.1 of WRF was used. The model ran in three domains with 27,9 , and $3 \mathrm{~km}$ spatial resolution, respectively, and 35 vertical levels. The innermost domain spans from $-11 \mathrm{E}$ to $5 \mathrm{E}$ and from $35 \mathrm{~N}$ to $45 \mathrm{~N}$ (Figure 1), thus covering the Iberian Peninsula and the Balearic Islands, with 442 grid points at $x$-dimension and 391 at $y$-dimension. Since the vertical profiles of the hydrometeors are crucial for the radiative transfer calculations in the microwave region, the Goddard's microphysical scheme [18] was used for microphysics, as this scheme contains 5 types of hydrometeors (cloud ice, cloud water, rain, snow, and graupel). Additional details of the model setup are given in Table 1 . 
TABLE 1: NWP model description.

\begin{tabular}{|c|c|}
\hline Version & 3.1 ARW \\
\hline Domains & 3 \\
\hline Spatial resolution (domains) & $27 \mathrm{~km} \quad 9 \mathrm{~km} \quad 3 \mathrm{~km}$ \\
\hline Grid points (domains) & $162 x-151 y \quad 307 x-271 y \quad 442 x-391 y$ \\
\hline Temporal resolution (domains) & $3 \mathrm{~h} \quad 3 \mathrm{~h} \quad 30 \mathrm{~min}$ \\
\hline Vertical levels & 35 \\
\hline Microphysical scheme & Goddard scheme \\
\hline Radiation scheme (long/short) & RRTM scheme/Dudhia scheme \\
\hline Cumulus parameterization (dom 1 ) & Grell-Devenyi ensemble scheme \\
\hline Surface layer option & Monin-Obukhov scheme \\
\hline Land scheme & Unified Noah land-surface model \\
\hline Boundary layer option & YSU scheme \\
\hline Innermost domain coordinates & $-11 \mathrm{E}$ to $5 \mathrm{E}, 35 \mathrm{~N}$ to $45 \mathrm{~N}$ \\
\hline
\end{tabular}

TABLE 2: Standard emissivity values for the vegetation types found in the innermost domain of the simulations.

\begin{tabular}{lccccccccc}
\hline & Vegetation Type & $10 \mathrm{~h}$ & $10 \mathrm{v}$ & $23 \mathrm{~h}$ & $23 \mathrm{v}$ & $36 \mathrm{~h}$ & $36 \mathrm{v}$ & $89 \mathrm{~h}$ & $89 \mathrm{v}$ \\
\hline 1 & Urban/built up land & 0.880 & 0.930 & 0.845 & 0.875 & 0.830 & 0.875 & 0.885 & 0.925 \\
2 & Dry cropland, pasture & 0.925 & 0.955 & 0.920 & 0.945 & 0.925 & 0.945 & 0.940 & 0.965 \\
3 & Irrigated cropland, pasture & 0.845 & 0.900 & 0.855 & 0.895 & 0.860 & 0.895 & 0.900 & 0.920 \\
5 & Cropland/grassland mosaic & 0.905 & 0.930 & 0.880 & 0.910 & 0.850 & 0.900 & 0.890 & 0.920 \\
6 & Cropland/woodland mosaic & 0.875 & 0.925 & 0.895 & 0.925 & 0.905 & 0.930 & 0.935 & 0.945 \\
7 & Grassland & 0.905 & 0.945 & 0.895 & 0.930 & 0.895 & 0.925 & 0.895 & 0.925 \\
8 & Shrubland & 0.860 & 0.945 & 0.870 & 0.935 & 0.880 & 0.935 & 0.930 & 0.945 \\
9 & Mixed grassland/shrubland & 0.910 & 0.945 & 0.905 & 0.935 & 0.910 & 0.935 & 0.945 & 0.955 \\
10 & Savanna & 0.885 & 0.910 & 0.895 & 0.915 & 0.905 & 0.920 & 0.915 & 0.925 \\
11 & Deciduous broadleaf forest & 0.935 & 0.960 & 0.940 & 0.955 & 0.940 & 0.955 & 0.965 & 0.970 \\
12 & Deciduous needleleaf forest & 0.860 & 0.935 & 0.760 & 0.875 & 0.700 & 0.845 & 0.760 & 0.890 \\
13 & Evergreen broadleaf forest & 0.940 & 0.975 & 0.915 & 0.945 & 0.915 & 0.940 & 0.920 & 0.945 \\
14 & Evergreen needleleaf forest & 0.925 & 0.965 & 0.915 & 0.950 & 0.915 & 0.945 & 0.935 & 0.960 \\
15 & Mixed forest & 0.965 & 0.980 & 0.960 & 0.975 & 0.955 & 0.970 & 0.885 & 0.900 \\
19 & Barren/sparsely vegetated & 0.805 & 0.895 & 0.805 & 0.895 & 0.820 & 0.905 & 0.855 & 0.935 \\
21 & Wooded tundra & 0.935 & 0.940 & 0.905 & 0.930 & 0.870 & 0.885 & 0.815 & 0.835 \\
\hline
\end{tabular}

In order to produce the input needed for the SDSU simulations, the corresponding geophysical parameters for the initialization are extracted from WRF.

The model output parameters that were used as inputs for the SDSU simulations are as follows.

Surface Parameters. Surface temperature, surface pressure, wind speed at $10 \mathrm{~m}$, skin temperature, surface type (land/ocean), vegetation type, and soil moisture.

Atmospheric Parameters. Height, pressure, (potential) temperature, cloud ice, cloud water, rain water, graupel ice content, and snow ice content.

All chosen parameters are based in the requisites of the SDSU, except the vegetation type, which is the extra variable chosen to be used in the emissivity calculation functions.

\section{Method: Emissivity Ensemble Approach}

The SDSU calculates surface emissivity over water bodies applying a model that takes into account the parameters previously mentioned (wind speed, sea surface temperature, etc.). On the other hand, over land surface emissivity is synthesized simply by a weighted average of water emissivity and a fixed value of 0.9 , where soil moisture serves as the averaging weight. However, in the original version, the soil moisture is ignored and the 0.9 value is considered for all land pixels. Initially, some tests were performed (not shown) using soil moisture, but the resulted emissivity values were extremely low, causing significant errors to $T_{b}$ calculation. The value (0.9) originally adopted for the simulations over land, close to the real emissivity values of many surface types, still in many circumstances is far from accurate since the emissivity value is often close to 1 , or on the contrary, due to high values of soil moisture in bare soil surfaces, it can be lower than 0.8 .

Concerning the vegetation type dependence, the first test is a rather simple approach, made by giving arbitrary values in emissivity and based on the fact that generally it increases as the vegetation increases [19]. In other words, the bare soil surface type areas had been given the lowest values (0.70) and the broadleaved forests the highest (0.995), using 


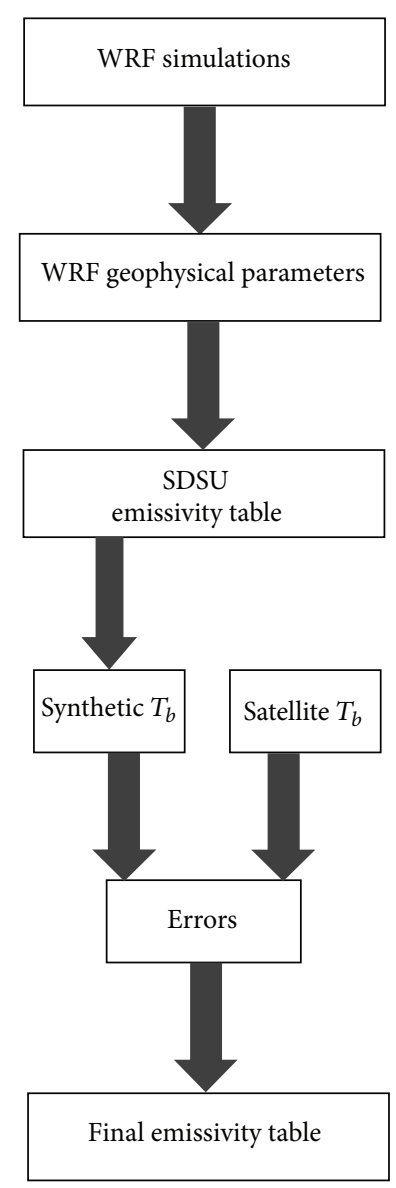

FIGURE 2: Schematic of the method proposed.

the vegetation categories (land use types) of WRF based on USGS 24 categorization. The advantage in comparison with the original version of SDSU is that in this case each pixel has a different emissivity value depending on a parameter (vegetation) that affects microwave emissivity, while the original version has a uniform value of 0.9 for all pixels over land, regardless of the type of land use.

With the purpose of making the first test using arbitrary emissivity values, the cloud-free land pixels were selected to be compared with the $T_{b}$ observations from the corresponding satellite (AMSR-E) pixels. After the first test showed some improvement, still with notable differences between frequencies and/or polarizations, new tests were made with 10 different emissivity values for each vegetation type and for each sensor channel (8 different channels), with a step of 0.005 between these emissivity values. Subsequently, after comparing with the corresponding AMSR-E channels, the emissivity values that gave the smallest errors in the $T_{b}$ values arose, resulting in a table (Table 2) of values, one for each vegetation type for all 8 channels. A schematic presentation of the method is shown in Figure 2.

The derived emissivity values, shown in Table 2, are higher for the vertical polarization channels in comparison with those of the horizontal polarization channels. The differences vary between 0.005 and 0.15 , depending on vegetation type. This rule is consistent with the table shown by [20], where the average emissivity values over six sites with different land use are presented. It should be noted that the big differences in vegetation type 12 in Table 2 concern a single pixel.

The simulations with the SDSU are performed for 3 selected cases over Spain (see Table 3), on December 18, 2010; February 15, 2011; and March 15, 2011. In all cases, there were reports of significant rainfall from the national meteorological service of Spain (AEMET). In Figure 3, the $\mathrm{CMORPH}$ data rainfall rate for the chosen cases is presented in 0.25-degree spatial resolution, for the closest 3hour period to the corresponding AMSR-E overpass. The selection of cases is also related to the future use of this study's results, which is to create a precipitation retrieval algorithm based on a database of hydrometeor profiles. For the first test, the case of 18 December, 2010, was used (case 1 ), and then the values of the emissivity table outcome were implemented in the simulations of the other two cases.

The resulting $T_{b}$ values for each case are then compared with the ones derived by simulations without changing the emissivity considered over land, to check if there are significant differences and improvements in the simulated brightness temperatures. The comparison is also done against the available AMSR-E overpasses over the study area, where the most adequate of them were chosen, one for each case study, all three at noon. Thus, the new emissivity prior can be evaluated indirectly through the comparison between the simulated $T_{b}$ values and the observed ones. Moreover, there is also comparison with the SDSU results after using the TELSEM emissivity monthly values over the study area. Figure 4 shows the maps with the emissivity values of TELSEM, used for the SDSU simulation of the three selected cases (i.e., February, March, and December monthly values) for the $89 \mathrm{GHz}-\mathrm{V}$ channel and the corresponding values resulting from the proposed method. The TELSEM values have $0.25^{\circ}$ resolution, resulting in poor delineation of the coastline in comparison with the $3 \mathrm{~km}$ resolution of the proposed method; nonetheless, they include seasonal variation, an important factor that is not present in the simple method of this study. However, no significant differences, apart from the coastline, which is expected, are observed between the TELSEM and the new method and it seems that the proposed method makes a physical sense.

The simulated fields can be produced every 30 minutes, based on the temporal resolution of the WRF model output files for the innermost domain, and for all cases the files with the closest to the overpass's UTC time were chosen.

\section{Results}

The comparison is made for all the land pixels and is among AMSR-E measurements, simulations with the SDSU original version (with one uniform value of land emissivity for all land pixels), and SDSU simulations with various values of land emissivity. 
TABLE 3: Study cases.

\begin{tabular}{lcc}
\hline Date & Description & Daily maximum precipitation \\
\hline 18 December 2010 & Heavy rainfall in Andalucía & Malaga 133 mm \\
15 March 2011 & Heavy rainfall in S Spain & Cordoba 52 mm \\
15 February 2011 & Heavy rainfall in SE Spain & Gerona 98 mm \\
\hline
\end{tabular}

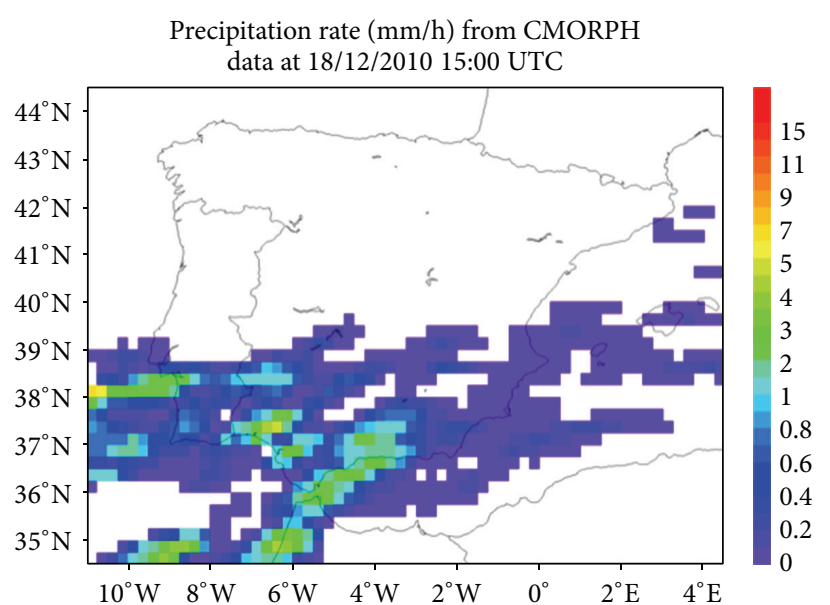

(a)

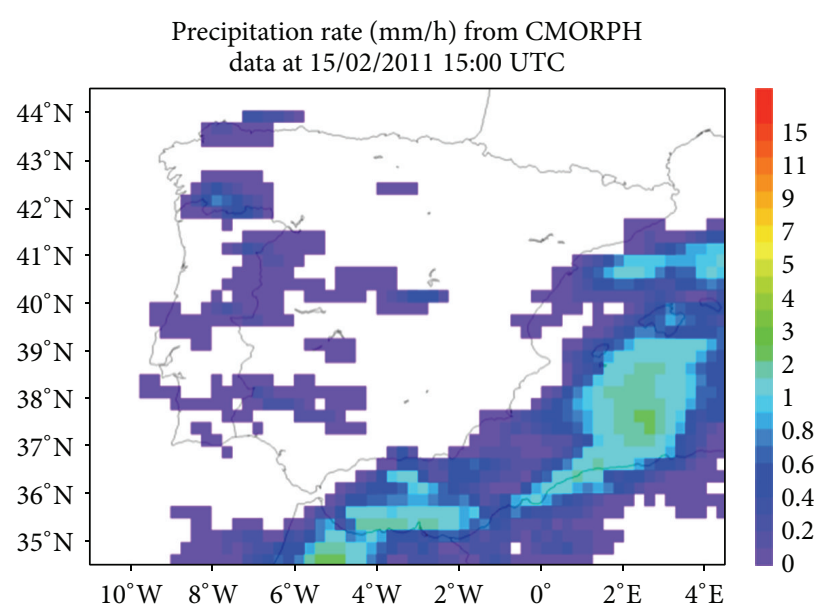

(b)

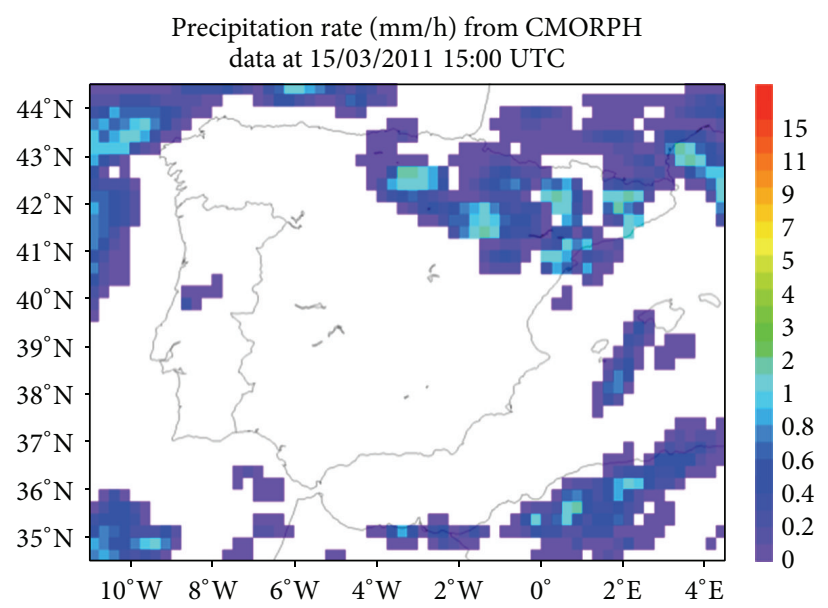

(c)

FIGURE 3: Precipitation over Spain based on CMORPH $3 \mathrm{hr}$ data with 0.25 -degree resolution for all 3 cases.

In Figure 5, the frequency distribution of $T_{b}$ values over land is presented, for all 8 channels, regarding the case of 18th of December 2010. In this figure, there are 8 different plots for each channel of AMSR-E $(10.65 \mathrm{GHz}, 23.8 \mathrm{GHz}, 36.5 \mathrm{GHz}$, and $89 \mathrm{GHz}$, all for both horizontal and vertical polarization). This is the case that was used as base to create the table with the emissivity values.

For all frequencies, the differences between AMSR-E and the SDSU $T_{b}$ 's of the original version are more evident at the channels of vertical polarization. The frequency distribution of these SDSU values is placed in colder temperatures, indicating the inaccuracy of the emissivity value originally used. Obviously, 0.9 is a rather small value for emissivity over land, especially for the vertical polarization, regardless of the frequency. The distribution of the SDSU values computed using the table of emissivity values is a lot closer to that of the satellite values, for all 4 frequencies. It can be seen that there is an improvement in all vertical resolution channels. Similarly, the $T_{b}$ values after using the TELSEM emissivity atlases are closer to the satellite measurements for all vertical channels, compared with the results after using the original SDSU emissivity.

On the other hand, in the horizontal polarization channels the differences were not that apparent, especially for the $23.8 \mathrm{GHz}$ and the $36.5 \mathrm{GHz}$ channels. However, still there is a place for improvement for the other two channels $(10.65 \mathrm{GHz}$ and $89 \mathrm{GHz}$ ) made by the use of the table of emissivity values. Again, the SDSU originally underestimated the $T_{b}$ 


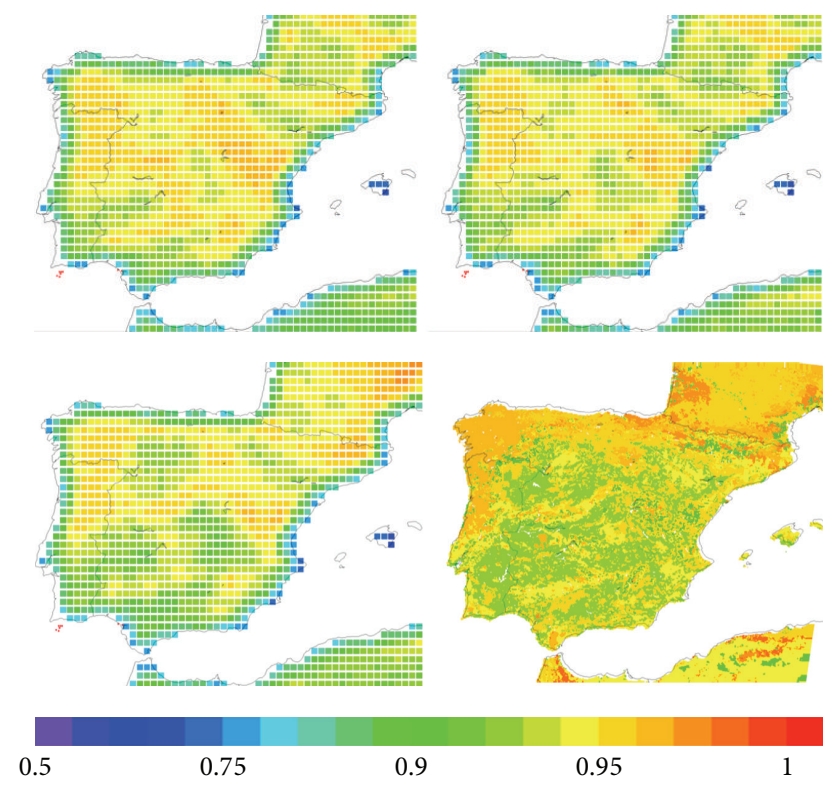

FIGURE 4: Examples of emissivity values (all images refer to $89 \mathrm{GHz}$ V) used for SDSU simulations. Top left: TELSEM February, top right: TELSEM march, bottom left: TELSEM December, and bottom right: proposed method's values.

values, although the differences were not that notable as in the vertical polarization channels. Regarding the results after using TELSEM values, on 1 ( $89 \mathrm{GHz}$ ) of 4 horizontal channels there was better agreement with the observed satellite values.

Although WRF seems to simulate adequately the storms that were selected for this study, even a slight spatial miss in the simulation of rain and clouds could lead to significant difference between observed and simulated $T_{b}$ values. Tables 4 and 5 show the correlation coefficient (using the Pearson method) and the RMS error in the clear sky pixels and the rainy/cloudy pixels, respectively, for all cases and methods and in comparison with AMSR-E, in order to evaluate the results in both situations.

In Table 4, it is observed that in all the channels there is an improvement regarding the RMS error, since all channels resulted in smaller RMSE values, after using the emissivity values table for the simulations. Furthermore, correlation also seems to improve for all frequencies, denoting that the simulations with the modifications in SDSU produce $T_{b}$ values closer to the satellite measurements. On the other hand, the spatial correlation for the TELSEM values is not as good as for the method proposed and in some channels even worse than the original SDSU version. This difference is probably due to the lower resolution and highlights the need for higher resolution emissivity products; however, this result needs more cases in order to have a certain conclusion. Also, it should be noted that the biggest difference in the correlation coefficient between TELSEM and the proposed method appears in the $36.5 \mathrm{GHz}(\mathrm{V})$, while in the $10.65 \mathrm{GHz}(\mathrm{V})$ and $89 \mathrm{GHz}(\mathrm{V})$ channels the difference from the proposed method and the original SDSU version's is significant too. Furthermore, for all methods the values of the correlation coefficient that are calculated in the high-resolution channels are relatively low.

In Table 5, the results for the first case regarding rainy/cloudy pixels are similar to those of Table 4; however, the differences in the values of the correlation coefficient between the proposed method and the TELSEM climatology values are smaller. Moreover, the values of the RMS error are higher and the ones of the correlation coefficient are lower for all methods, especially for the $89 \mathrm{GHz}$ channels that are affected by the precipitation and the presence of ice in the clouds, indicating poor correlation. These results imply that there is a direct dependence on the ability of the WRF model to reproduce accurately clouds and precipitation patterns.

In Figure 6, the same frequency distribution plots as in Figure 5 are presented, but for the case of 15 February 2011 (case 2). In this figure, it can be seen that using various values of emissivity (proposed method) improves the $T_{b}$ calculation, in terms of frequency distribution, clearly in the vertical polarization channels. Regarding the values after using TELSEM atlases, it seems that they have a good agreement in all vertical channels, however being not better than those of the proposed method. These results show the necessity of a different approach in emissivity estimation over land, since up to date the $T_{b}$ 's are underestimated by the SDSU. This is also obvious at the images of Figure 7, where the spatial distribution of $T_{b}$ 's in the study area for the channels $36.5 \mathrm{GHz}(\mathrm{V})$ and $89 \mathrm{GHz}(\mathrm{V})$, respectively, is presented (Figure $7(\mathrm{~b})$ ), together with the differences between the two methods (fixed value-land cover value). The improvement appears in the figure of the new emissivity results in comparison with the AMSR-E measurements, while the corresponding image with the initial emissivity value appears much different and with lower values of brightness temperature. Such a difference is not evident though for the lower emissivity channels $(10.65 \mathrm{GHz}$ and $23.8 \mathrm{GHz})$ in corresponding Figure 7(a). However, for all vertical polarization channels, it seems that the new method results in higher values of brightness temperature, given that the differences have obviously negative values (bluish colours).

Again, as in case 1, the corrections in emissivity do not affect notably the horizontal polarization channels, since there was already good agreement with the satellite measurements (Figure 6). This is more obvious in $23.8 \mathrm{GHz}$ and $36.5 \mathrm{GHz}$ channels, while the other two channels show some more notable improvement. Nonetheless, the proposed method results seem to have better concurrence with the AMSR-E values than the TELSEM ones. In Figures 7(a) and $7(\mathrm{~b})$, where the $10.65 \mathrm{GHz}, 23.8 \mathrm{GHz}$, and $36.5 \mathrm{GHz}$ plots over the area of study are shown, it can be seen that the improvement is difficult to be identified. Also, the plots with the differences show that there are both positive (reddish) and negative values. However, in the figure for the $89 \mathrm{GHz}$ frequency, there are some noteworthy differences towards an improvement, in comparison with the $T_{b}$ values after using the original SDSU emissivity over land.

For this case, Figure 8 can be seen additionally with Tables 4 and 5, presenting the corresponding scatter plots. The results regarding rainy/cloudy pixels are alike to those of case 1, with higher correlation coefficient values for almost 

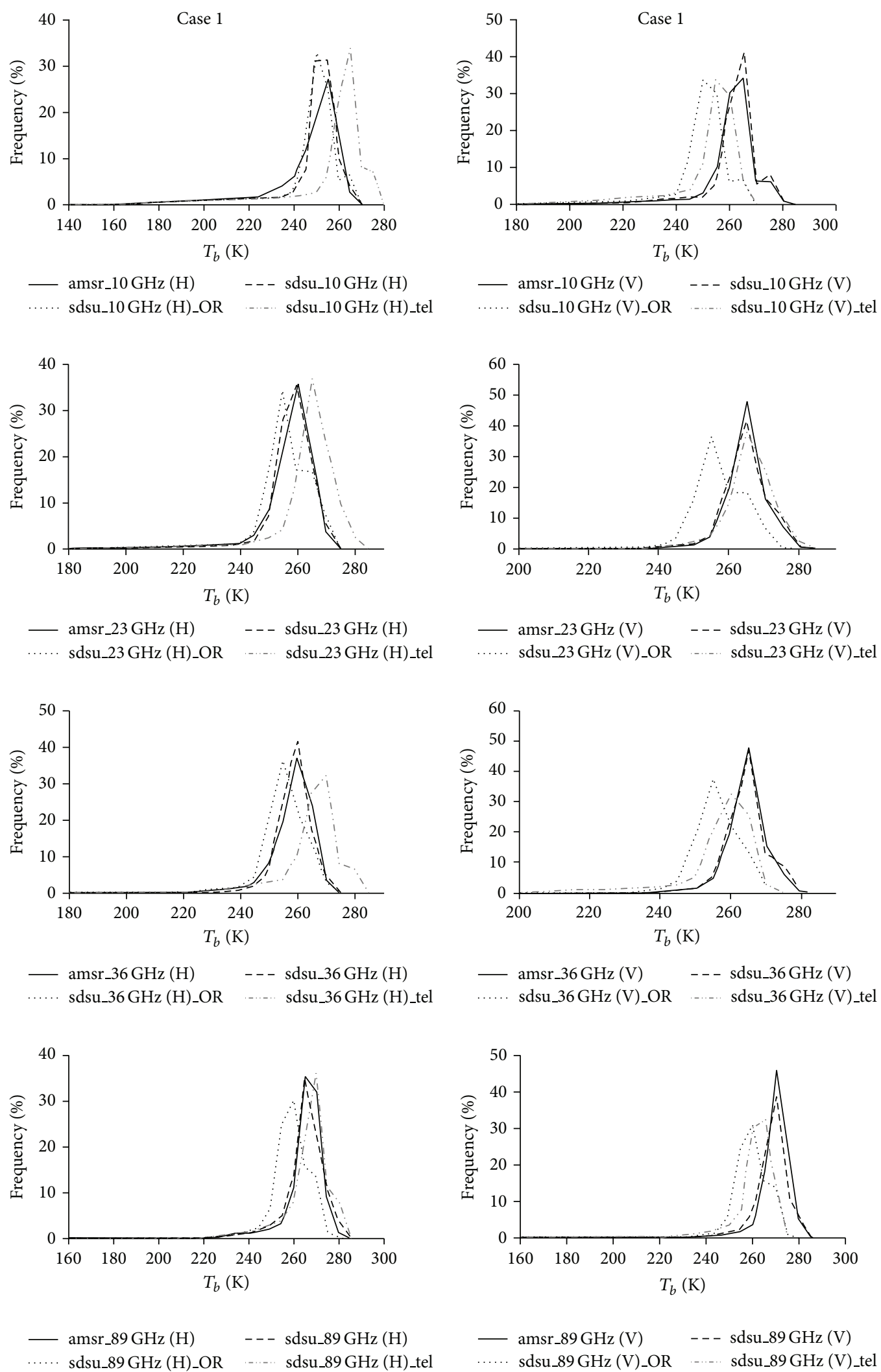

$$
\begin{aligned}
& \text { — } \text { amsr_89 GHz (V) _ - - sdsu_89 GHz (V) } \\
& \text {.... sdsu_89 GHz (V)_OR ....... sdsu_89 GHz (V)_tel }
\end{aligned}
$$

FIGURE 5: Results for December 18, 2010. Frequency distribution of $T_{b}$ 's of land pixels for all 8 channels, for AMSR-E (solid line), the original version of SDSU (dotted line-noted as OR) the new emissivity version (dashed line), and TELSEM based simulations (dot-dashed grey line noted as tel). 


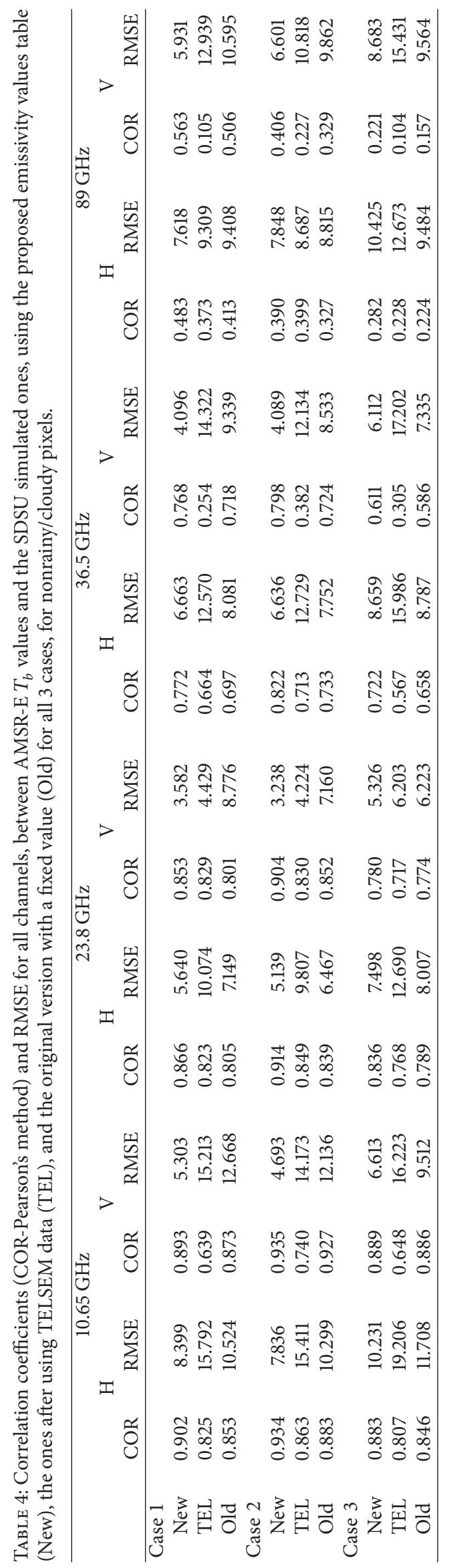




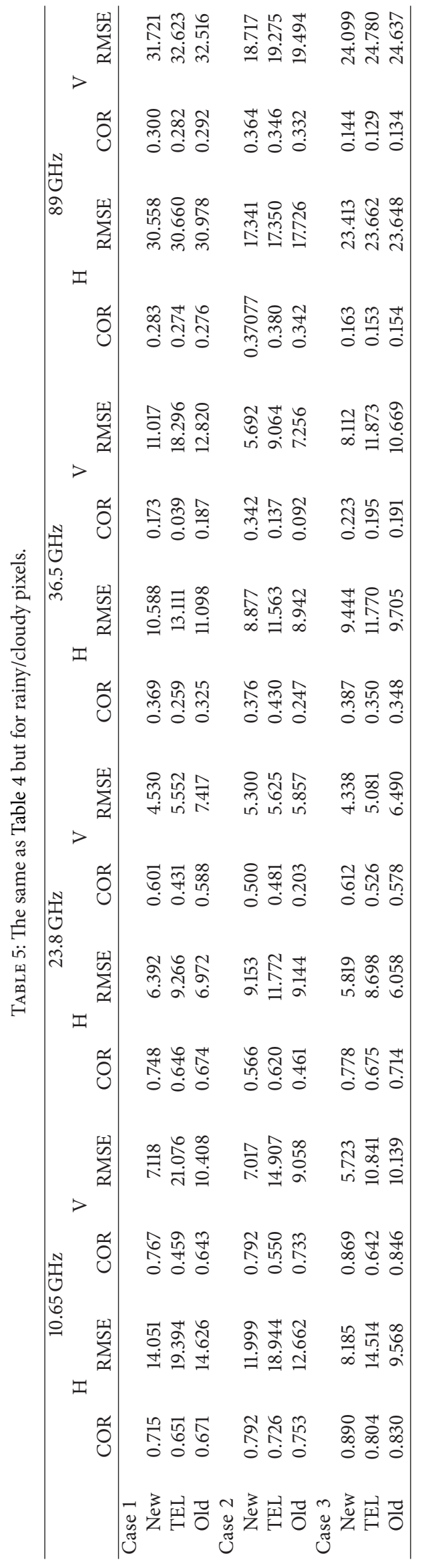



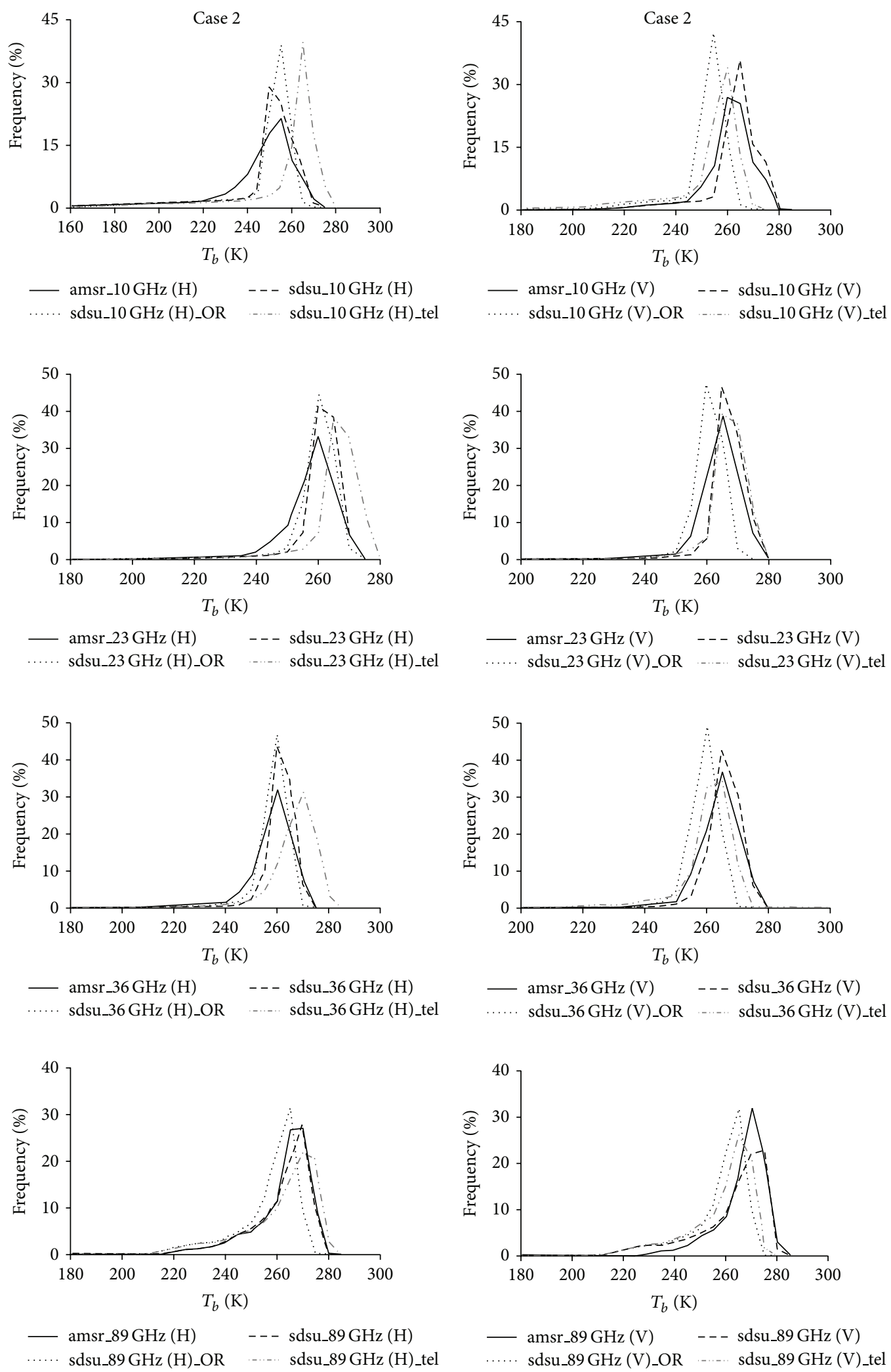

FIgURE 6: Same as in Figure 5, for the case of 15 February 2011. 

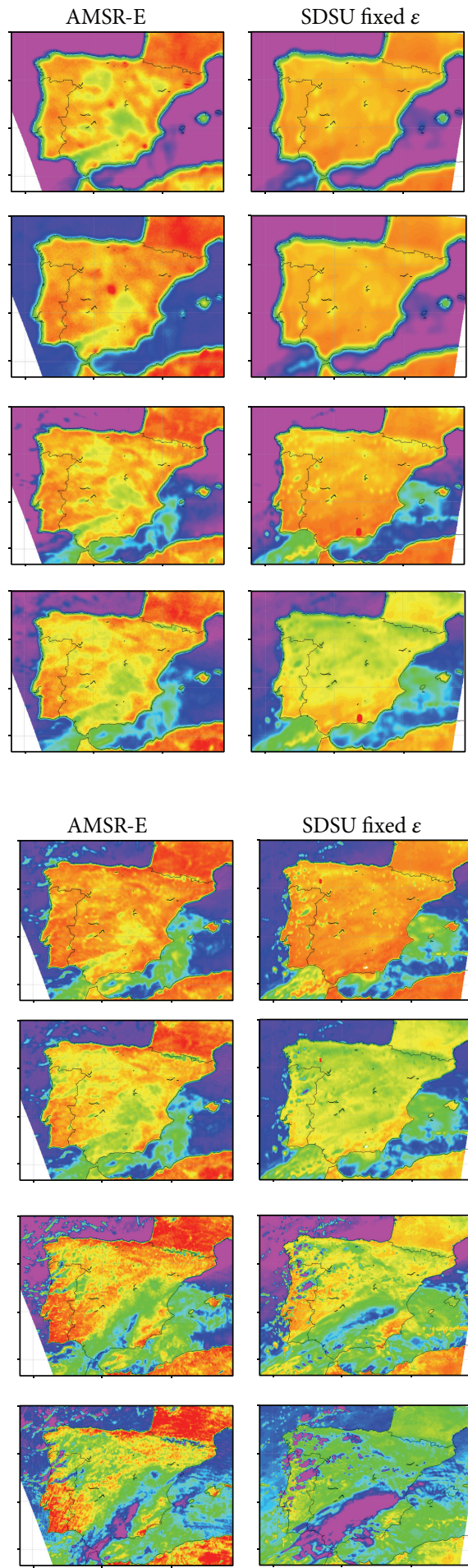

SDSU fixed $\varepsilon$
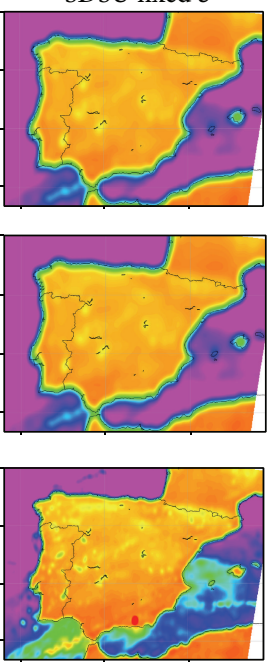

$\operatorname{SDSU}$ fixed $\varepsilon$
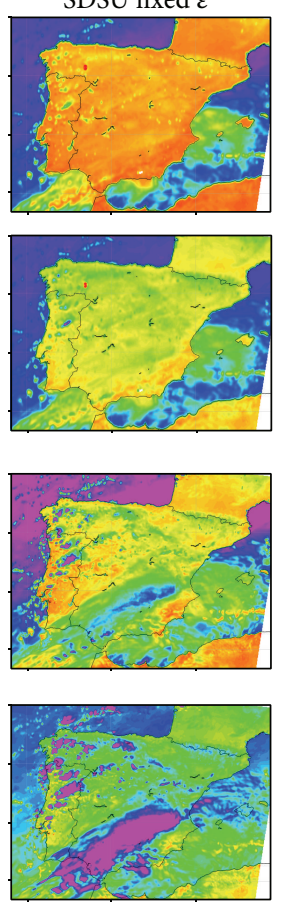

SDSU land cover $\varepsilon$
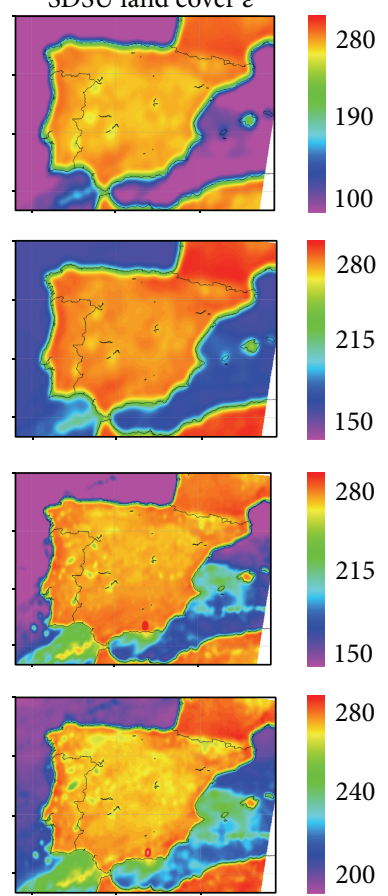

(a)
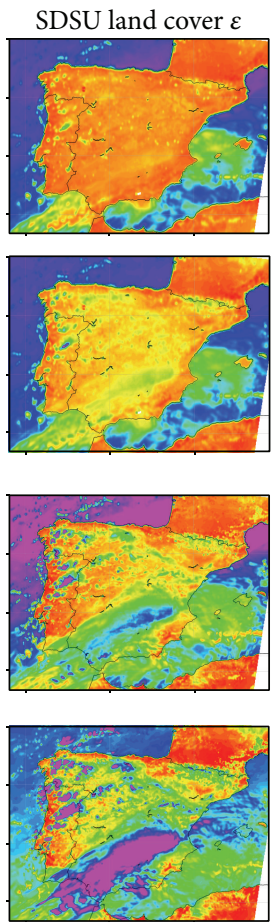

(b)
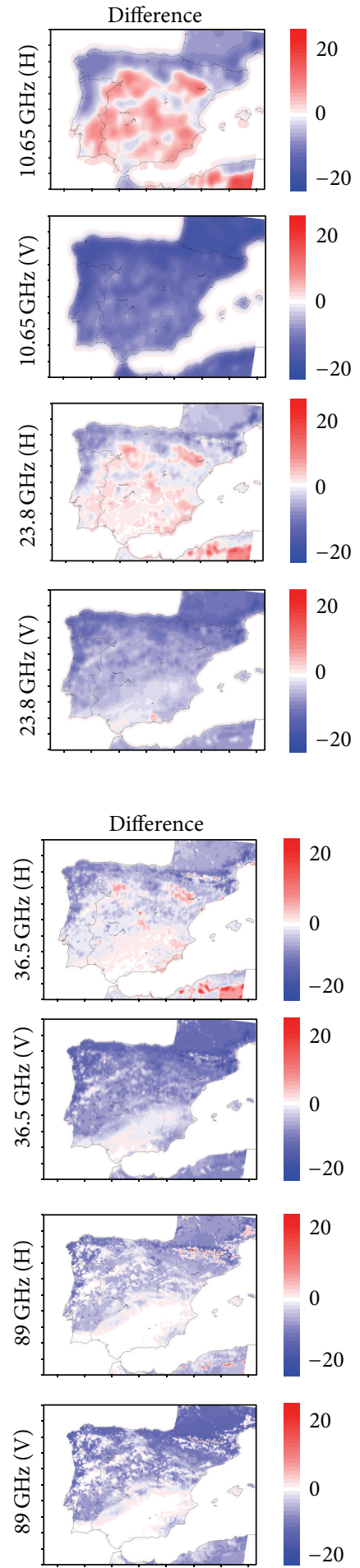

FIGURE 7: (a) From left to right, upper 2 panels: $T_{b}$ at $10.65 \mathrm{GHz}(\mathrm{H}-\mathrm{V})$ for AMSR-E, SDSU (original version), SDSU (emissivity table version), and differences between the two versions (values in K). Down 2 panels: $T_{b}$ at $23.8 \mathrm{GHz}(\mathrm{H}-\mathrm{V})$ for AMSR-E, SDSU (original version), SDSU (emissivity table version), and differences between the two versions (values in K). All images are for the case of 15 February 2011. (b) From left to right, upper 2 panels: $T_{b}$ at $36.5 \mathrm{GHz}(\mathrm{H}-\mathrm{V})$ for AMSR-E, SDSU (original version), SDSU (emissivity table version), and differences between the two versions (values in K). Down 2 panels: $T_{b}$ at $89 \mathrm{GHz}(\mathrm{H}-\mathrm{V})$ for AMSR-E, SDSU (original version), SDSU (emissivity table version), and differences between the two versions (values in K). All images are for the case of 15 February 2011. 

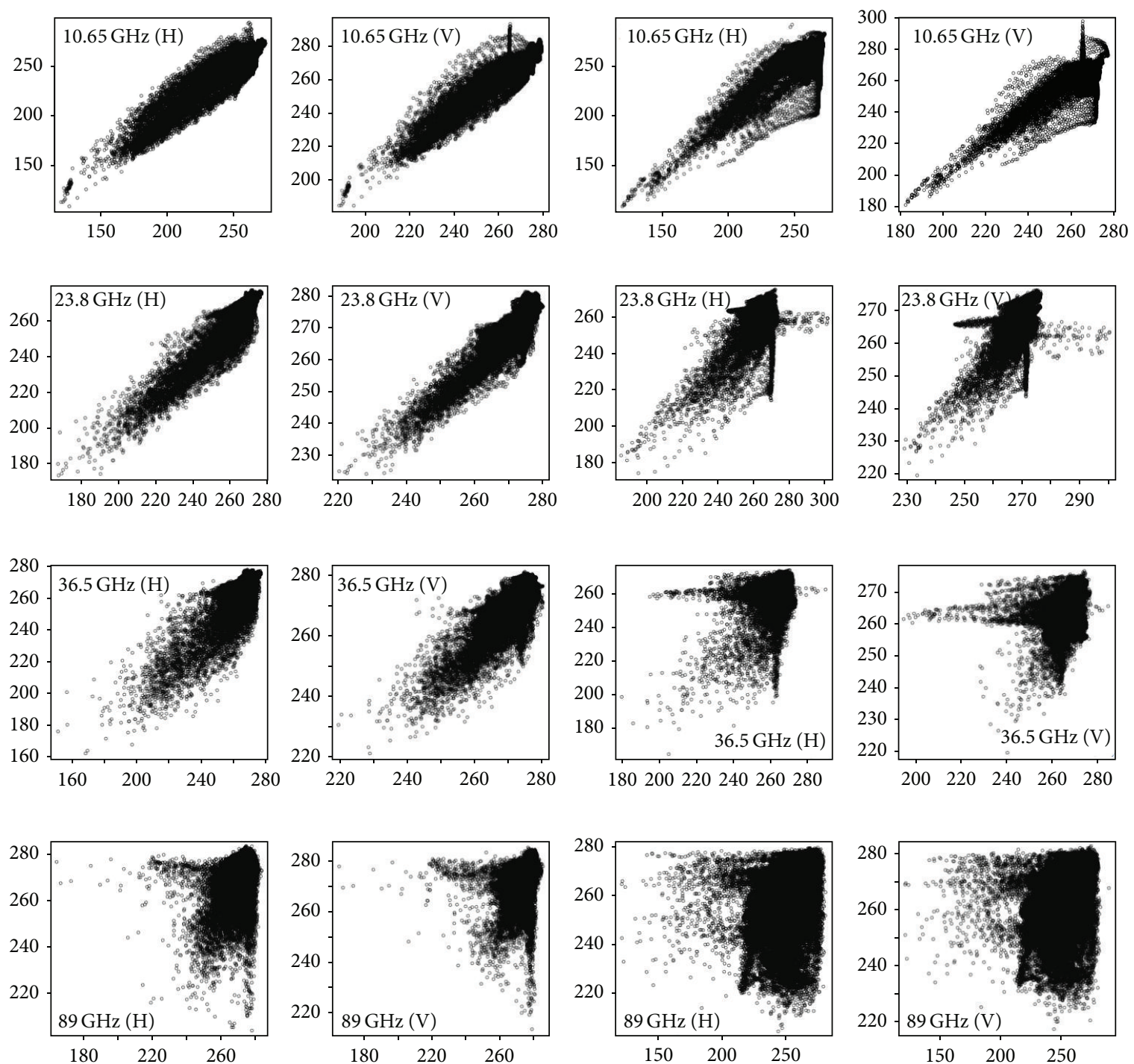

FIGURE 8: Case of 15 February 2011: scatter plots of SDSU (emissivity table version) against AMSR-E: column 1-horizontal channels clear sky pixels, column 2-vertical channels clear sky pixels, column 3-horizontal channels rainy/cloudy pixels, and column 4-vertical channels rainy/cloudy pixels for all frequencies.

all channels for the simulations with the proposed emissivity values, with the exception of the $89 \mathrm{GHz}(\mathrm{H})$ channel where the correlation between simulated and observed $T_{b}$ values was slightly better for the TELSEM emissivity values. Regarding TELSEM emissivity values, again the spatial correlation is not as good as in the case of the proposed method, or even the original SDSU emissivity, revealing again the resolution drawback. As in case 1, the biggest difference in correlation coefficient value with the proposed method occurs in the $36.5 \mathrm{GHz}(\mathrm{V})$, with the $10.65 \mathrm{GHz}(\mathrm{V})$ and $89 \mathrm{GHz}(\mathrm{V})$ channels having also significant differences. In relation to RMS errors, the horizontal channels had slightly bigger values for all frequencies.

On the other hand, Table 5 for this case shows that in 3 of the horizontal channels the TELSEM values have slightly better correlation with the AMSR-E observations than the values simulated after using the proposed method.
It should be noted that this is the case with the highest number of rainy/cloudy pixels in comparison with the other two cases. Again the lower correlation coefficient values and the higher RMS error values are calculated for the highresolution channels, while the RMS error values are generally high for all channels and methods, indicating the dependence on WRF model's ability to reproduce clouds and rainfall. This is also evident in Figure 8 (rightmost columns), where the scatter plots for the rainy/cloudy pixels show a rather random distribution.

Similar are the results regarding the third case of 15 March 2011 (Figure 9). As in the other two cases, the frequency distribution of the original SDSU $T_{b}$ values has significant differences with the AMSR-E measurements, in all vertical polarization channels, while the proposed version's plot line finds better agreement with that of the satellite. Once again, there is an underestimation of the brightness temperature 

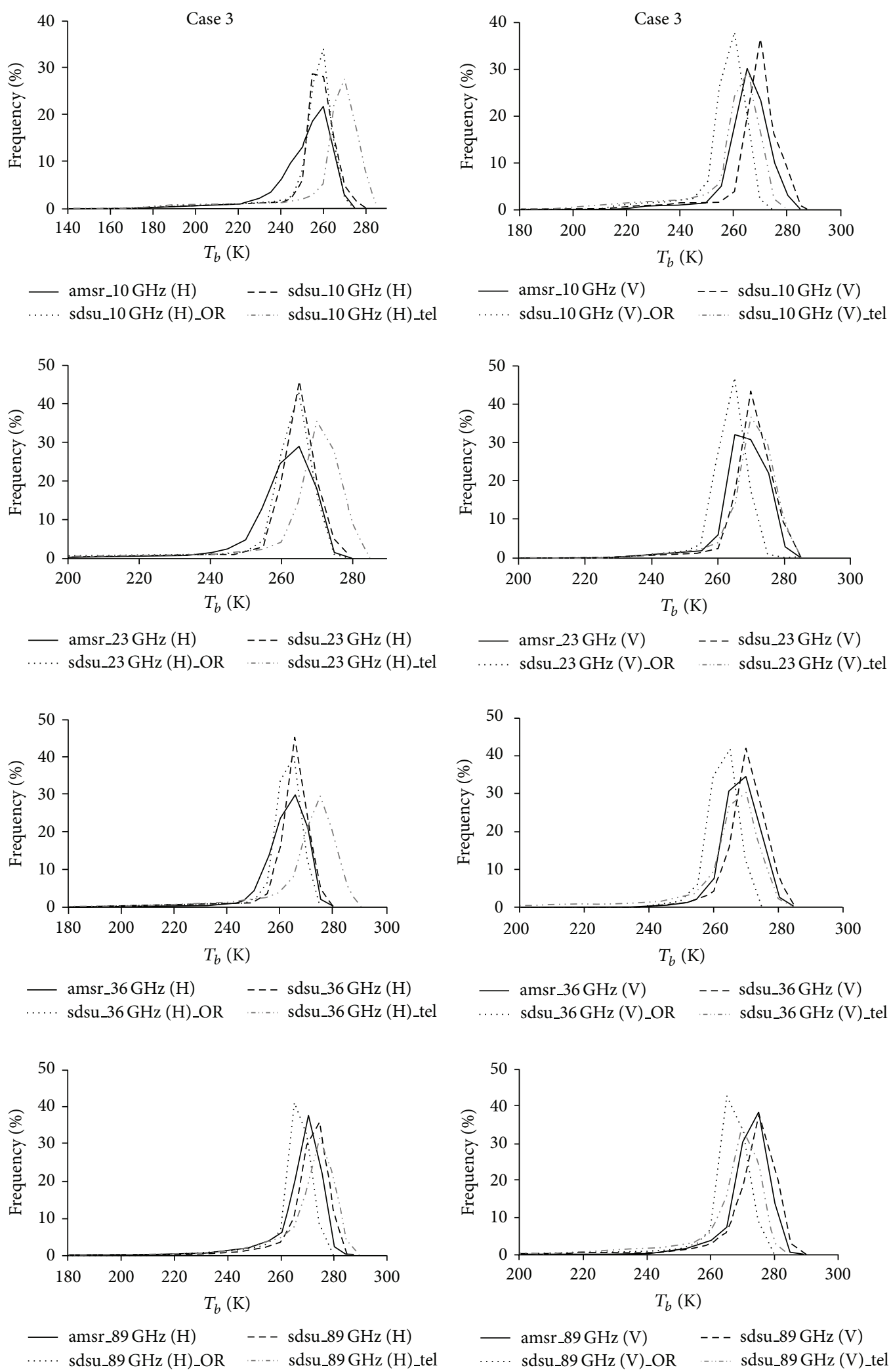

FIgure 9: The same as in Figure 5, for the case of 15 March 2011. 
values by the initial simulations, those without any changes in emissivity values. As for the horizontal channels, the improvement is smaller or almost does not exist, like in the case of $23 \mathrm{GHz}$ channel, where the plot lines of the original version and the new one are almost identical. Again, TELSEM derived values have good agreement with AMSR-E for the vertical channels, and for 1-2 frequencies better than that of the proposed method. For the horizontal channels the agreement was not that good, while in those channels the proposed method has obviously better results. Regarding correlation and RMS errors, the results are similar to the other two cases for the clear sky pixels, with the correlation coefficient values for the $36.5 \mathrm{GHz}(\mathrm{V})$ being the lower and the error values higher for the $89 \mathrm{GHz}$ channels. Additionally, for the rainy/cloudy pixels the results were similar to the ones for case 1, with the proposed method showing better correlation than TELSEM and a generally poor correlation for the highresolution channels.

\section{Conclusions and Further Work}

The first results after applying a new emissivity prior at the Satellite Data Simulator Unit over Iberian Peninsula are presented. In place of CRM results that are used as inputs by the SDSU, the outputs from the WRF model in high-resolution $(3 \mathrm{~km})$ are implemented. Four AMSRE microwave frequencies are simulated, in horizontal and vertical polarization. The original version of SDSU does not represent accurately the microwave surface emissivity over land, since a single value for all land pixels is adopted. For that reason, a simple method to estimate the appropriate emissivity value using WRF vegetation type is proposed, in order to have an emissivity value for each frequency per vegetation type. After using a table of emissivity values three study cases are simulated and the resultant $T_{b}$ values are compared with the corresponding satellite measurements. Also, the TELSEM monthly emissivity atlases are used for additional comparison.

The results of the comparison between the simulated values and the satellite measurements showed that SDSU originally underestimates the $T_{b}$ values in all vertical channels and that the correction proposed improves the simulations, as this shown in frequency distribution plots. Also, the RMS errors decrease and the correlation improves after simulating with a table of emissivity values, derived from the proposed method. This is more evident in the clear sky pixels for all the studied cases, while for the rainy/cloudy pixels the differences are smaller and there is the exception of one channel for one case with the original version giving slightly better correlation.

Regarding the horizontal channels, there is also improvement in two channels, $10.65 \mathrm{GHz}$ and $89 \mathrm{GHz}$. Again the SDSU underestimates the $T_{b}$ values when the original version is used. The other two channels, $23.8 \mathrm{GHz}$ and $36.5 \mathrm{GHz}$, showed little or no improvement since there was good agreement with the satellite values when the original SDSU was used. Correlation is better for all the frequencies for the clear sky pixels and for all cases, while similarly to the vertical channels, for the rainy/cloudy pixels the differences in the correlation coefficient values are smaller.

Nonetheless, there are limitations regarding the use of this method. The emissivity values are based on the comparison with the AMSR-E so they are instrument dependent. Furthermore, diurnal or seasonal variations are not included.

In addition, the comparison of the proposed method with the TELSEM based values showed generally better results in all channels and all cases for the clear sky pixels, with the exception of the $89 \mathrm{GHz}(\mathrm{H})$ for the case of 12 February 2011. Regarding the rainy/cloudy pixels, the results were similar with the ones for the clear sky pixels for two of the cases, while for the case of 12 February 2011, which had the largest amount of rainy/cloudy pixels, TELSEM based values showed better correlation with the satellite observations. These results indicate a normal dependence on the model's skill on rainfall and cloud forecasting. It should be noted, though, that using climatology values from TELSEM for near-real-time operations could be a crude approximation. Nonetheless, the lower resolution of the data resulted in low values of spatial correlation, indicating the need for higher resolution emissivity atlases.

Continuing this work, there is also comparison with summer cases to be done with the purpose to study the correspondence of the correction in the SDSU surface emissivity over land, in such cases. Another perspective is to combine our method with the emissivity atlases provided by [8] although the difference in resolution is an issue that has to be arranged, with vegetation type (or other parameter) based downscaling. Moreover, the results of this study and the following ones will be of great importance, since the objective of the use of SDSU is to reclaim the results of these studies and gradually develop a rain retrieval algorithm.

\section{Conflict of Interests}

The authors declare that there is no conflict of interests regarding the publication of this paper.

\section{Acknowledgments}

The authors acknowledge Projects CGL2010-20787-C02-01, CGL2010-20787-C02-02, CENIT PROMETEO (MICCIN), PPII10-0162-554 (JCCM), and LE176A11-2 (JCyL).

\section{References}

[1] P. A. Kucera, E. E. Ebert, F. J. Turk et al., "Precipitation from space: advancing earth system science," Bulletin of the American Meteorological Society, vol. 94, no. 3, pp. 365-375, 2013.

[2] F. J. Tapiador, F. J. Turk, W. Petersen et al., "Global precipitation measurement: methods, datasets and applications," Atmospheric Research, vol. 104-105, pp. 70-97, 2012.

[3] H. Masunaga, T. Matsui, W. Tao et al., "Satellite data simulator unit: a multisensor, multispectral satellite simulator package," Bulletin of the American Meteorological Society, vol. 91, no. 12, pp. 1625-1632, 2010. 
[4] F. Karbou, "Two microwave land emissivity parameterizations suitable for AMSU observations," IEEE Transactions on Geoscience and Remote Sensing, vol. 43, no. 8, pp. 1788-1795, 2005.

[5] T. Wilheit, C. D. Kummerow, and R. Ferraro, "Rainfall algorithms for AMSR-E," IEEE Transactions on Geoscience and Remote Sensing, vol. 41, no. 2, pp. 204-214, 2003.

[6] C. Prigent, E. Jaumouillé, F. Chevallier, and F. Aires, "A parameterization of the microwave land surface emissivity between 19 and $100 \mathrm{GHz}$, anchored to satellite-derived estimates," IEEE Transactions on Geoscience and Remote Sensing, vol. 46, no. 2, pp. 344-352, 2008.

[7] T. J. Hewison, "Airborne measurements of forest and agricultural land surface emissivity at millimeter wavelengths," IEEE Transactions on Geoscience and Remote Sensing, vol. 39, no. 2, pp. 393-400, 2001.

[8] F. Karbou, C. Prigent, L. Eymard, and J. R. Pardo, "Microwave land emissivity calculations using AMSU measurements," IEEE Transactions on Geoscience and Remote Sensing, vol. 43, no. 5, pp. 948-958, 2005.

[9] B. Lin and P. Minnis, "Temporal variations of land surface microwave emissivities over the atmospheric radiation measurement program southern great plains site," Journal of Applied Meteorology, vol. 39, no. 7, pp. 1103-1116, 2000.

[10] S. J. English and T. J. Hewison, "A fast generic millimetrewave emissivity model," in Proceedings of the Microwave Remote Sensing of the Atmosphere and Environment (SPIE '98), vol. 3503, pp. 288-300, September 1998.

[11] J. C. Morland, D. I. F. Grimes, and T. J. Hewison, "Satellite observations of the microwave emissivity of a semi-arid land surface," Remote Sensing of Environment, vol. 77, no. 2, pp. 149164, 2001.

[12] J. C. Morland, D. I. F. Grimes, G. Dugdale, and T. J. Hewison, "The estimation of land surface emissivities at $24 \mathrm{GHz}$ to $157 \mathrm{GHz}$ using remotely sensed aircraft data," Remote Sensing of Environment, vol. 73, no. 3, pp. 323-336, 2000.

[13] F. Aires, C. Prigent, F. Bernardo, C. Jiménez, R. Saunders, and P. Brunel, "A tool to estimate land-surface emissivities at microwave frequencies (TELSEM) for use in numerical weather prediction," Quarterly Journal of the Royal Meteorological Society, vol. 137, no. 656, pp. 690-699, 2011.

[14] T. Matsui, X. Zeng, W. Tao, H. Masunaga, W. S. Olson, and S. Lang, "Evaluation of long-term cloud-resolving model simulations using satellite radiance observations and multifrequency satellite simulators," Journal of Atmospheric and Oceanic Technology, vol. 26, no. 7, pp. 1261-1274, 2009.

[15] H. Masunaga, M. Satoh, and H. Miura, "A joint satellite and global cloud-resolving model analysis of a Madden-Julian Oscillation even: model diagnosis," Journal of Geophysical Research D: Atmospheres, vol. 113, no. 17, Article ID D17210, 2008.

[16] W.-K. Tao, D. Anderson, J. Chern et al., "The Goddard multiscale modeling system with unified physics," Annales Geophysicae, vol. 27, no. 8, pp. 3055-3064, 2009.

[17] W. C. Skamarock, J. P. Klemp, J. Dudhia et al., "A description of the advanced research WRF version 3," NCAR Technical Note NCAR/ TN-4751STR, 2008.

[18] W.-K. Tao, J. Simpson, and M. McCumber, "An ice-water saturation adjustment," Monthly Weather Review, vol. 117, no. 1, pp. 231-235, 1989.

[19] F. Karbou, E. Gérard, and F. Rabier, "Microwave land emissivity and skin temperature for AMSU-A and -B assimilation over land," Quarterly Journal of the Royal Meteorological Society, vol. 132, no. 620, pp. 2333-2355, 2006.

[20] H. Yang and F. Weng, "Error sources in remote sensing of microwave land surface emissivity," IEEE Transactions on Geoscience and Remote Sensing, vol. 49, no. 9, pp. 3437-3442, 2011. 

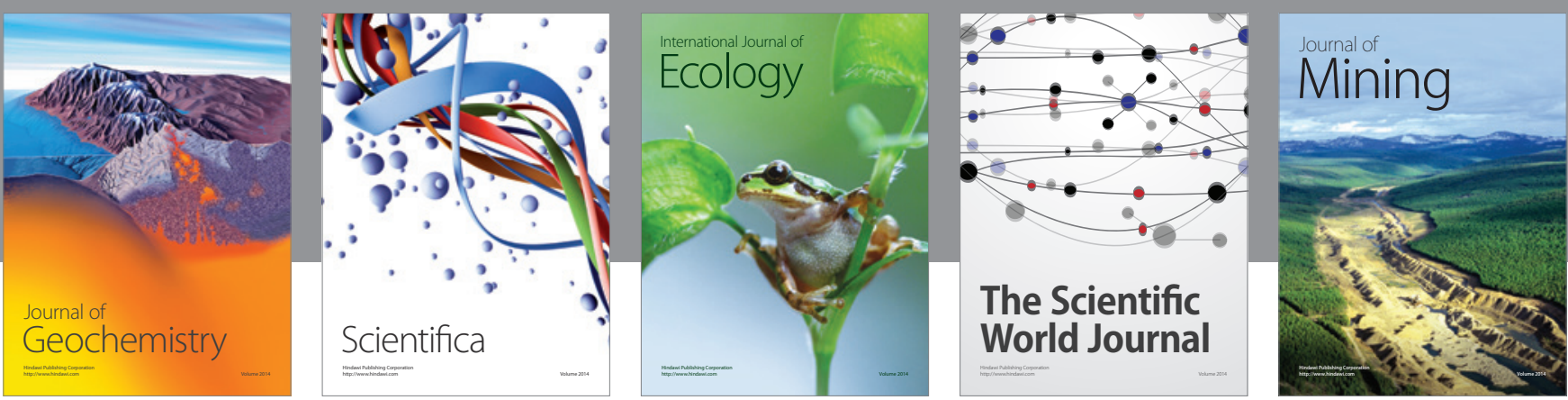

The Scientific World Journal
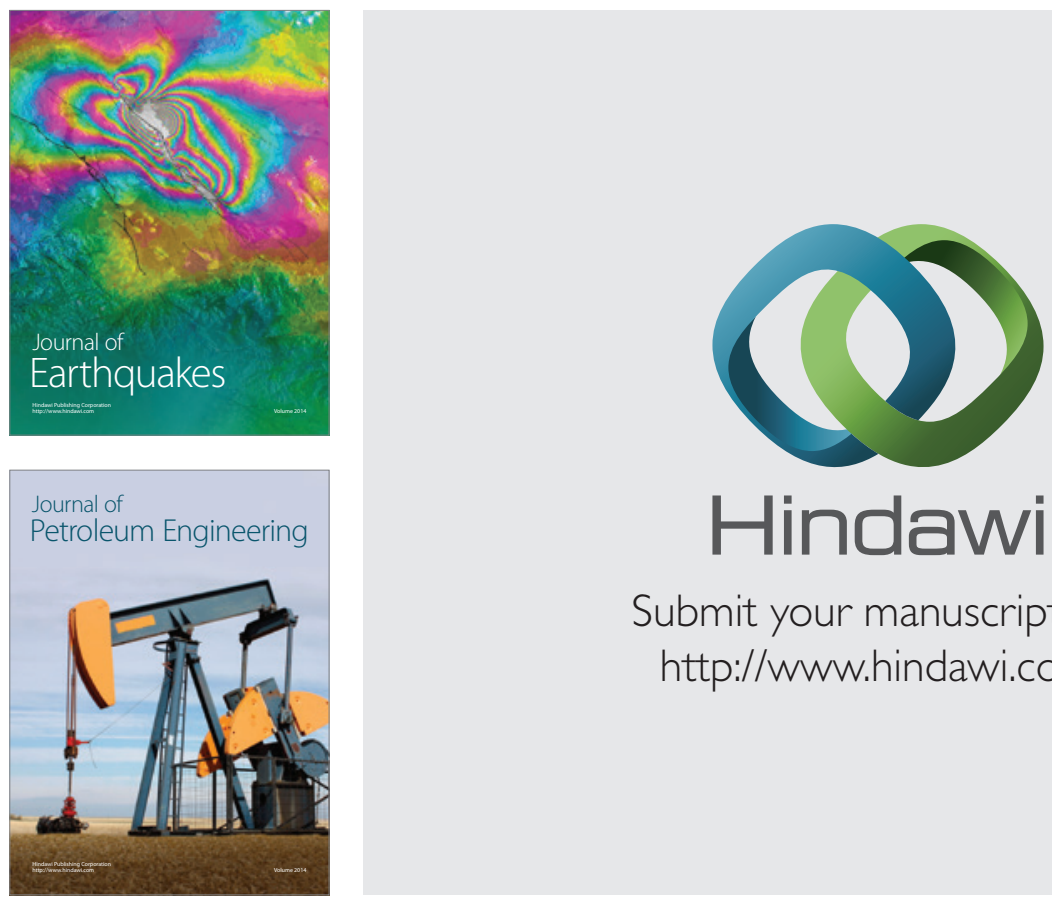

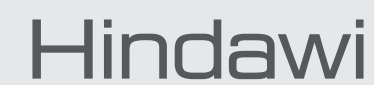

Submit your manuscripts at

http://www.hindawi.com
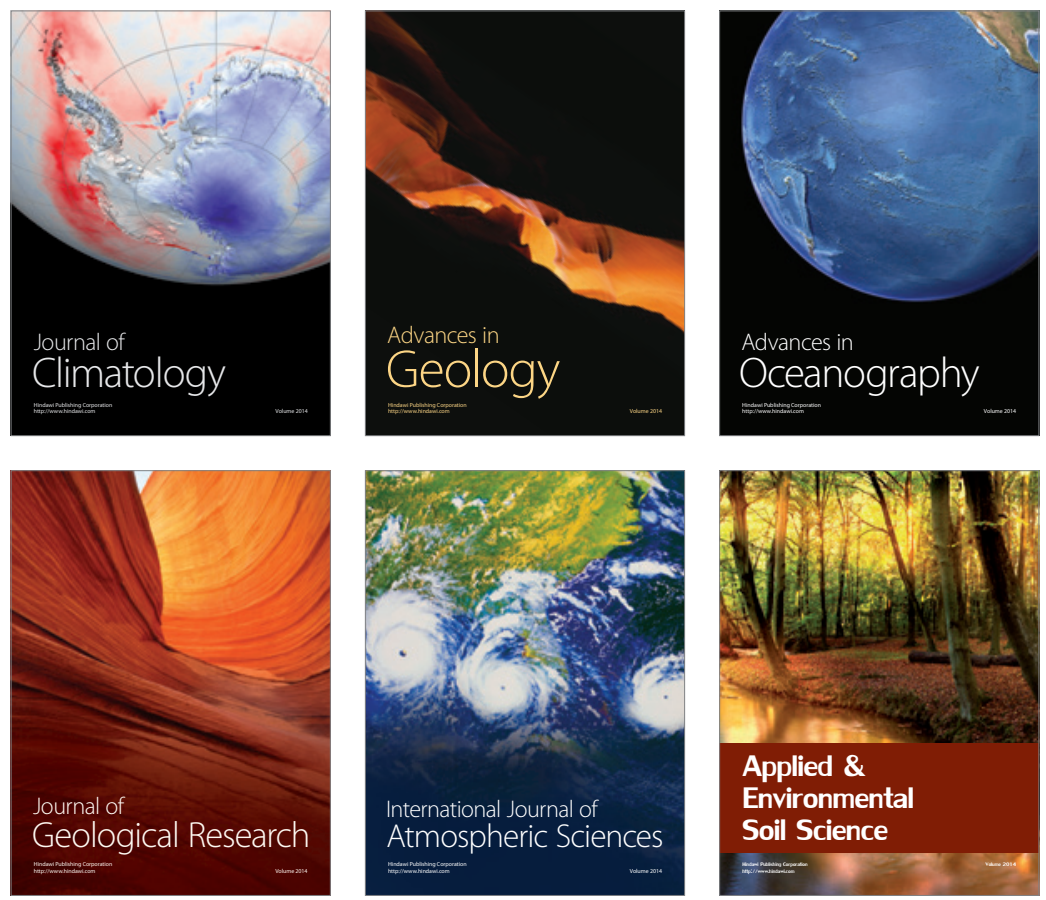
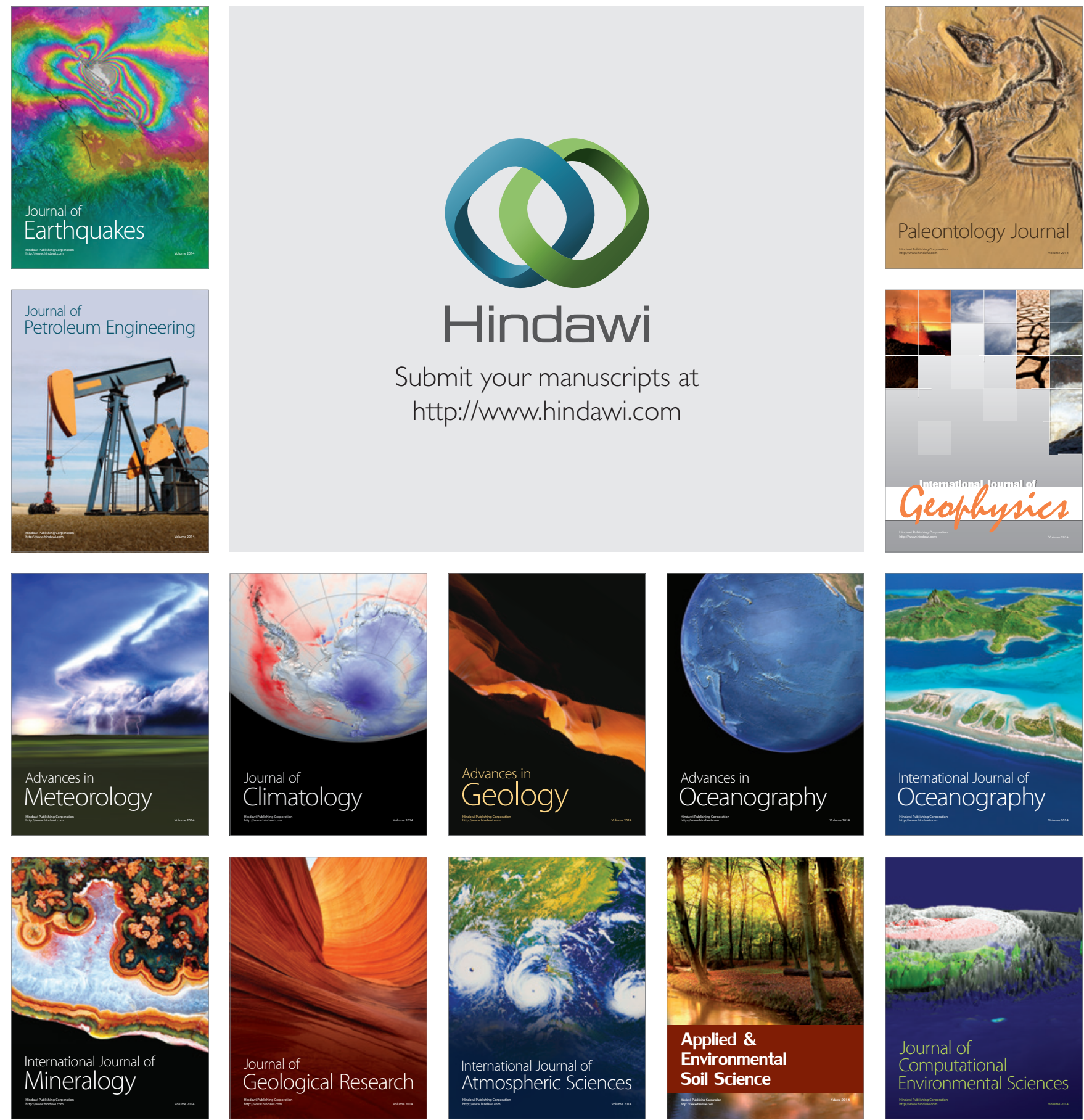